\title{
Effet de Calliandra calothyrsus associé au PEG 6000 sur la digestibilité in vitro de la paille de riz traitée à l'extrait de cendre chez la chèvre
}

\author{
F. TENDONKENG ${ }^{1 *}$, J. LEMOUFOUET ${ }^{1}$, E. MIEGOUE $^{1}$, F. E. N. MATUMUINI ${ }^{2}$, \\ B. Z. FOGANG ${ }^{3}$, A. CHOUNNA ${ }^{1}$, F. D. NDONKOU ${ }^{1}$ et E. PAMO TEDONKENG ${ }^{1}$ \\ ${ }^{1}$ Laboratoire de Production et Nutrition Animales (LAPRONAN), Département de Productions Animales, \\ FASA, Université de Dschang, B.P. 222 Dschang, Cameroun. \\ ${ }^{2}$ Institut Supérieur d'Agronomie et de Biotechnologie (INSAB), \\ Université des Sciences et Techniques de Masuku, B.P. 941 Franceville, Gabon. \\ ${ }^{3}$ Institut Supérieur de Technologies, Département de Génie Alimentaire et de Control de qualité. \\ Université de Ngaoundéré, B.P. 455 Ngaoundéré, Cameroun. \\ *Auteur correspondant ; E-mail: ftendonkeng@yahoo.fr ; f.tendonkeng@univ-dschang.org
}

\section{RESUME}

L'étude de l'effet de Calliandra calothyrsus associé au PEG 6000 sur la digestibilité in vitro de la paille de riz traitée à l'extrait de cendre a été conduite de mars à août 2016. La présente étude a été initiée avec pour objectif de contribuer à l'amélioration des connaissances sur la valorisation des résidus de récoltes dans l'alimentation des ruminants. A cet effet, l'analyse de la composition chimique a été faite selon les méthodes décrites par l'AOAC. Une source de liquide ruminal (caprin) et une source de protéine (Calliandra calothyrsus) associée ou non au polyéthylène glycol ont été utilisées pour cette étude. Le liquide ruminal d'une chèvre naine de Guinée a été collecté et incubé avec $500 \mathrm{mg}$ d'échantillon (350 mg de paille de riz non traitées ou traitées à l'extrait de cendre associé ou non à $150 \mathrm{mg}$ de Calliandra calothyrsus et au polyéthylène glycol) dans un bain marie à $39{ }^{\circ} \mathrm{C}$, selon la méthode de gaz-test. Cette étude a montré que l'ajout de Calliandra calothyrsus a permis de rehausser la teneur en matière azotée totale de la paille de riz quelle que soit la ration considérée. Par ailleurs, tous les paramètres (la production de gaz, la DIVMS, la DIVMO...) de la digestibilité in vitro de la paille de riz non traitée et de la paille de riz traitée à l'extrait de cendre ont augmenté significativement $(\mathrm{p}<0,05)$ avec l'ajout de Calliandra calothyrsus associé au PEG.

(C) 2018 International Formulae Group. All rights reserved.

Mots clés : Calliandra calothyrsus, digestibilité in vitro, extrait de cendre, paille de riz, PEG.

\section{Effect of Calliandra calothyrsus associated with PEG 6000 on in vitro digestibility of rice straw treated with the ash extract in goat}

\begin{abstract}
A study of the effect of Calliandra calothyrsus associated with PEG 6000 on in vitro digestibility of rice straw treated with the ash extract was carried out between March and August 2016. The aim of this study was to valorise the farm residues in ruminant feeding. Thus, chemical composition analysis of rice straw was done according to the AOAC methods. A source of ruminal liquid (Goat) and a source of protein (Calliandra
\end{abstract}


calothyrsus) associated or not with polyethylene glycol 6000 with the rice straw untreated or treated with ash extract were used for this study. Ruminal fluid of the African Dwarf goat was collected and incubated with 500 $\mathrm{mg}$ of feed sample $(350 \mathrm{mg}$ of rice straw untreated or treated with ash extract, associated with $150 \mathrm{mg}$ of Calliandra calothyrsus and polyethylene glycol) at $39{ }^{\circ} \mathrm{C}$ in a water bath, as per gas-test method. The results of this study showed that addition of Calliandra calothyrsus leads to an increase in total nitrogen content of the rice straw. Indeed, all the parameters such as gas production, in vitro of organic matter digestibility (IVOMD), in vitro dry matter digestibility (IVDMD) of in vitro digestibility of untreated or treated rice straw with the ash extract increased significantly ( $\mathrm{p}<0,05$ ) with the addition of Calliandra calothyrsus associated with PEG 6000. (c) 2018 International Formulae Group. All rights reserved.

Keywords: Calliandra calothyrsus, ash extract, in vitro digestibility, PEG, rice straw.

\section{INTRODUCTION}

Le riz, deuxième céréale cultivée dans le monde produit environ 377 millions de tonnes de résidus de récolte annuellement (FAO, 2009). Au Cameroun, la production rizicole nationale fournit environ 250000 tonnes de paille (Yaning et al., 2012). Cependant, la quasi-totalité de cette paille est enfouie dans le sol sous forme d'amendement ou brûlée avec pour corollaire la pollution de l'environnement (Lemoufouet et al., 2016). Les études antérieures ont montré que la paille de riz est riche en fibre, pauvre en énergie facilement utilisable, en protéines brutes ( 2 à $7 \%$ ), en minéraux et a une teneur élevée en silice ( 8 à 16\%), ce qui a pour conséquence une faible ingestion et digestibilité (Heuzé et Tran, 2013). Or bien traitée et complémenté cette paille pourrait constituer une ressource alimentaire non négligeable pour les animaux, surtout pendant la saison sèche où le déficit fourrager est plus ressenti. Plusieurs méthodes ont été envisagées pour améliorer sa valeur nutritive, entre autre les traitements aux alcalins tels que, le $\mathrm{NaOH}, \mathrm{Ca}(\mathrm{OH})_{2}$ et l'ammoniac longtemps utilisés pour améliorer la valeur nutritive des fourrages pauvres. Toutefois, leurs indisponibilités, leurs coûts élevés et les difficultés de manipulations poussent les agro éleveurs à la recherche des produits disponibles et moins onéreux comme l'extrait de cendre.

La cendre, un résidu principalement basique issu de la combustion, de l'incinération de diverses matières organiques et minérales peut être utilisée pour le traitement des fourrages pauvres et peu digestibles. Sa composition varie en fonction du produit calciné et son origine. La cendre a plusieurs utilisations, entre autre, la fabrication du savon, des détergents et du vinaigre. Il est utilisé comme engrais et permet l'amendement des sols pauvres (Heuzé et Tran, 2013). De $\mathrm{pH}$ variant en fonction du combustible utilisé, il s'avère que le pouvoir alcalinisant des extraits de cendre reste très élevé grâce à leur teneur élevée en chaux $\left(\mathrm{Na}_{2} \mathrm{CO}_{3}\right)$ et en potasse $\left(\mathrm{K}_{2} \mathrm{CO}_{2}\right)$ qui pourrait avoir des effets bénéfiques sur la digestibilité des fourrages grossiers en alimentation animale. Le traitement de la paille de riz ne permettant pas à l'animal de satisfaire tous ses besoins, c'est ainsi que complémenter la paille traitée avec une source de protéine à l'instar des ligneux comme Calliandra calothyrsus pourra permettre d'atteindre des niveaux de production optimale (Pamo et al., 2005).

C. calothyrsus est un arbuste fourrager de la famille des légumineuses, originaire d'Amérique centrale. Il s'adapte parfaitement aux conditions pédoclimatiques du Cameroun, résiste à la sècheresse et est disponible toute l'année. Sa teneur en protéine brute peut atteindre 28,6\% MS (Pamo et al., 2005). Cependant l'efficacité de son utilisation n'est pas optimale chez les animaux en raison de sa teneur plus ou moins élevée en substances anti-nutritionnelles notamment les tanins. Les tanins sont des molécules naturellement synthétisées par les plantes, en réponse aux différents stress abiotiques et biotiques (Frutos et al., 2002). Ils peuvent influencer directement le microbiote ruminal et l'activité enzymatique, en réduisant la disponibilité des nutriments et les perfornances de l'animal. Pour atténuer l'effet nocif contenu dans les légumineuses, plusieurs méthodes ont été utilisées pour désactiver les tanins, notamment 
l'usage du PEG. En effet, Pamo et al. (2004) ont montré que la supplémentation de quelques graminées avec Calliandra calothyrsus en présence du PEG a amélioré la production de gaz et d'acides gras volatils de ces graminées. Ainsi, le traitement de la paille de riz et associé au Calliandra calothyrsus et au PEG 6000 pourrait améliorer sa digestibilité.

Le présent travail avait pour but d'évaluer l'effet de Calliandra calothyrsus associé au PEG 6000 sur la digestibilité in vitro de la paille de riz traitée ou non à l'extrait de cendre incubé avec le liquide ruminal caprin.

\section{MATERIEL ET METHODE \\ Zone de l'étude}

L'essai a été conduit de mars 2016 à août 2016 à la Ferme d'Application et de Recherche (FAR) et au Laboratoire de Nutrition et d'Alimentation Animales (Figure 1) de l'Université de Dschang. La ferme est située à $5^{\circ} 26^{\prime}$ latitude Nord et $10^{\circ} 26^{\prime}$ longitude Est, à une altitude de $1420 \mathrm{~m}$ dans la région de l'Ouest-Cameroun. Le climat de la localité est équatorial de type camerounien d'altitude. Les précipitations varient entre 1500 et $2000 \mathrm{~mm}$ et les températures oscillent entre 10 et $25^{\circ} \mathrm{C}$. La saison sèche va de mi-novembre à mi-mars et la saison des pluies de mi-mars à mi-novembre (Tendonkeng et al., 2011).

\section{Matériel animal}

Une chèvre naine de guinée adulte et vide, âgée de 18 mois, a été utilisée comme donneuse du liquide ruminal pour cette étude.

\section{Matériel végétal}

Le matériel végétal était constitué de la paille de riz (résidus de récolte) de variété NERICA3 qui a été collectée dans les parcelles expérimentales de l'Institut de Recherche et Agronomique pour le Développement (IRAD), d'une légumineuse à la montaison, Calliandra calothyrsus et des feuilles séchées de bananier-plantain récoltées dans les parcelles expérimentales de la FAR.

Six rations ont été utilisées dans cette étude :
R1 : Paille de riz non traitée (PRNT: Témoin);

R2: Paille de riz non traitée + feuilles de Calliandra $(\mathrm{PRNT}+\mathrm{Cc})$;

R3: Paille de riz non traitée + feuilles de Calliandra + PEG (PRNT + Cc +PEG) ;

$\mathrm{R} 4$ : Paille de riz traitée à l'extrait de cendre (PRT) ;

R5 : Paille de riz traitée à l'extrait de cendre + feuilles de Calliandra $(\mathrm{PRT}+\mathrm{Cc})$;

R6: Paille de riz traitée à l'extrait de cendre + feuilles de Calliandra + PEG (PRT+ $\mathrm{Cc}+\mathrm{PEG})$.

Un échantillon de $500 \mathrm{~g}$ de chaque ration a été prélevé et conservé pour les analyses de la composition chimique et la digestibilité in vitro. L'analyse de la composition chimique a été faite selon les méthodes décrites par l'AOAC (2000).

\section{Conduite de l'essai}

La dégradation in vitro a été faite selon la méthode et la procédure décrites par Menke et al. (1979) modifiées par Makkar (2002).

Préparation des échantillons et de la solution mère

Des échantillons (500 mg) ont été pesés en triple à l'aide d'une balance électrique de marque Kern 770, de portée 210 $\mathrm{g}$ et de sensibilité $0,0001 \mathrm{~g}$ puis, déposés au fond de seringues de $100 \mathrm{ml}$. Le tout a été recouvert par le piston de la seringue préalablement embaumé de vaseline pour faciliter son mouvement.

La solution mère a été préparée selon la méthode et la procédure décrite par Menke et al. (1979). Les différents réactifs entrant dans cette solution et leur volume sont les suivants :

$\begin{array}{ll}\text { Réactifs } & \text { Volumes }(\mathbf{m l}) \\ \text { Tampon phosphate } & 333 \\ \text { Macro minéral } & 333 \\ \text { Micro minéral } & 0,333 \\ \text { Rézasurine } 0,4 \% & 0,417 \\ \text { Eau distillée } & 732\end{array}$

Conditionnement et incubation des échantillons et de la solution mère

A la veille de la réalisation de l'essai, les échantillons et la solution mère fraîchement préparés selon la procédure cidessus décrite ont été placés dans un 
incubateur de marque Memmert à $39{ }^{\circ} \mathrm{C}$ pendant toute la nuit. De même, le bain marie était mis en marche et la température était contrôlée par deux thermostats de marque Lauda E300 réglés à $39{ }^{\circ} \mathrm{C}$.

Le matin, avant la collecte du liquide ruminal, la solution mère a été placée dans un bain marie à $39{ }^{\circ} \mathrm{C}$. Dans cette solution arrivait continuellement d'une bouteille de gaz un flux de $\mathrm{CO}_{2}$ dont la pression a été réglée à 4 bars. Le sulfure de sodium $(417 \mathrm{mg})$ et le $\mathrm{NaOH} 6 \mathrm{~N}(0,444 \mathrm{ml})$ ont été ajoutés à la solution mère qui a viré du bleu à l'incolore en passant par le rouge.

\section{Collecte du liquide ruminal et incubation}

Une chèvre naine de Guinée adulte et vide a été, au préalable, nourris pendant quinze jours avec les rations à tester. Chaque jour, l'animal recevait l'une des six rations différentes de celle de la veille.

Le liquide ruminal de la chèvre a été collecté juste après abattage au Laboratoire de Nutrition et Alimentation Animales de l'Université de Dschang très tôt le matin de la manipulation. Après chaque collecte, le liquide ruminal a été aussitôt filtré à l'aide d'un tissu de mailles $1 \mathrm{~mm}$ sous un flux de $\mathrm{CO}_{2}$ qui arrivait continuellement d'une bouteille de gaz et, pour la préparation de $2098,75 \mathrm{ml}$ d'inoculum; $700 \mathrm{ml}$ ont été prélevés et introduits dans la solution mère toujours sous le flux de $\mathrm{CO}_{2}$. Ce mélange (inoculum) a été homogénéisé pendant $10 \mathrm{~min}$ à l'aide d'une baguette magnétique. Quarante millilitres $(40 \mathrm{ml})$ de cet inoculum ont été prélevés et injectés dans chaque seringue à l'aide d'un distributeur de précision de marque Fortuna Optifix, puis l'ensemble a été placé dans le bain marie pour incubation.

L'incubation a duré 24 heures et les volumes de gaz produit ont été relevés après 3 h, $6 \mathrm{~h}, 9 \mathrm{~h}, 12 \mathrm{~h}, 18 \mathrm{~h}$, et $24 \mathrm{~h}$. La production de gaz était calculée et corrigée d'après la formule suivante (Menke et steingass, 1988):

$G P(m l / 200 m g M S)=\frac{\left(V_{24}-V_{o}-G P_{o}\right) \times 200 m g \times G P_{h}}{m \times M S}$

Avec :

$\mathrm{V}_{24}=$ Volume des gaz lu à 24 heures,

$\mathrm{V}_{0}=$ Volume de l'inoculum dans la seringue au début de l'incubation,
$\mathrm{GP}_{0}=$ Volume des gaz produits par le blanc à 24 heures,

$\mathrm{GP}_{\mathrm{h}}=$ Volume des gaz produits par le standard à 24 heures.

\section{Détermination de la digestibilité in vitro de la} matière sèche

A la fin de l'incubation, le contenu des seringues a été transféré dans les béchers de $600 \mathrm{ml}$ et ces seringues ont été lavées deux fois de suite avec deux portions de $15 \mathrm{ml} \mathrm{de}$ Neutral detergent solution (NDS) et vidé dans ces béchers. Les échantillons ont été portés à ébullition à feu doux pendant une heure et filtrés dans des creusets filtrants pré-tarés. Ces creusets ont été séchés à $103{ }^{\circ} \mathrm{C}$ pendant une nuit et pesés. Cette opération a permis de soustraire les micro-organismes des substrats plus ou moins non dégradés; car lorsqu'ils sont morts, ils sont généralement réutilisés dans le tractus digestif des ruminants. La digestibilité in vitro de la matière sèche (DIVMS) a été obtenue par la différence entre le poids du substrat incubé et le poids du résidu non dégradé après le traitement au NDS à la fin de l'incubation à partir de la formule suivante (Van Soest et Robertson, 1985) :

DIVMS $(\%)=\frac{\mathrm{Pe}-\mathrm{R}}{\mathrm{Pe}} \times 100$, où :

$\mathrm{P}_{\mathrm{e}}=$ Poids de l'échantillon incubé ;

$\mathrm{R}=$ Poids de l'échantillon après incubation.

Après 24 heures d'incubation, les gaz produits et corrigés par les gaz des tubes témoins ont été utilisés pour calculer la digestibilité in vitro de la matière organique (DIVMO) en utilisant l'équation de régression de Menke et Steingass (1988). Quant à l'énergie métabolisable (EM), elle a été calculée selon l'équation proposée par Markkar (2002).

DIVMO $(\%)=14,88+0,889 \mathrm{GP}+0,0651 \mathrm{C}$

$\mathrm{EM}(\mathrm{MJ} / \mathrm{Kg} \mathrm{MS})=2,20+0,136 \mathrm{GP}+0,057$ $\mathrm{PB}$, avec :

$\mathrm{GP}=$ Quantité de gaz produit après 24 heures d'incubation;

$\mathrm{PB}=$ Protéine Brute ;

$\mathrm{C}=$ Cendres.

Le facteur de cloisement (FC) qui est la quantité de la matière organique fermentée qui produit $1 \mathrm{ml}$ de gaz a été obtenu par calcul à partir de la formule suivante (Makkar, 2002): 
$F C(m g / m l)=\frac{M O D}{G P}$, où :

$\operatorname{MOD}(\mathrm{mg})=$ Matière Organique Dégradée ;

$\mathrm{GP}(\mathrm{ml})=$ Quantité des Gaz produits après 24 heures d'incubation.

La masse microbienne a été calculée à partir de la formule suivante (Makkar, 2002) :

MM (mg) = MOD $-($ GP $\times$ FS $)$, avec:

MOD $(\mathrm{mg})=$ Matière Organique Dégradée;

GP $(\mathrm{ml})=$ Quantité de Gaz Produit après 24 heures d'incubation;

$\mathrm{FS}=$ Facteur stoechiométrique $(2,20$ pour les fourrages).

Les Acides Gras Volatils (AGV) ont été obtenus par calcul à partir des formules suivantes (Makkar, 2002) :
AGV $(\mathbf{m m o l} / \mathbf{m l})=0,0239$ GP $-0,0601(\mathrm{en}$ absence du PEG)

AGV $(\mathbf{m m o l} / \mathbf{m l})=\mathbf{0 , 0 2 0 7 G P}+\mathbf{0 , 0 2 0 7}(\mathrm{en}$ présence du PEG)

Où, $\mathrm{GP}(\mathrm{ml})=$ Quantité de gaz produit après 24 heures d'incubation.

\section{Analyse statistique}

Les paramètres de la digestibilité des différentes rations ont été soumis à une analyse de variance (ANOVA) à un facteur (traitement) suivant le Modèle Linéaire Général (MGL) en utilisant le logiciel SPSS 20.0. Lorsque les différences existaient entre les traitements, les moyennes ont été séparées par le test de Duncan au seuil de 5\%. La comparaison des moyennes entre la paille de riz non traitée et celle traitée a été faite à l'aide du test «t» de Student au seuil de 5\%.

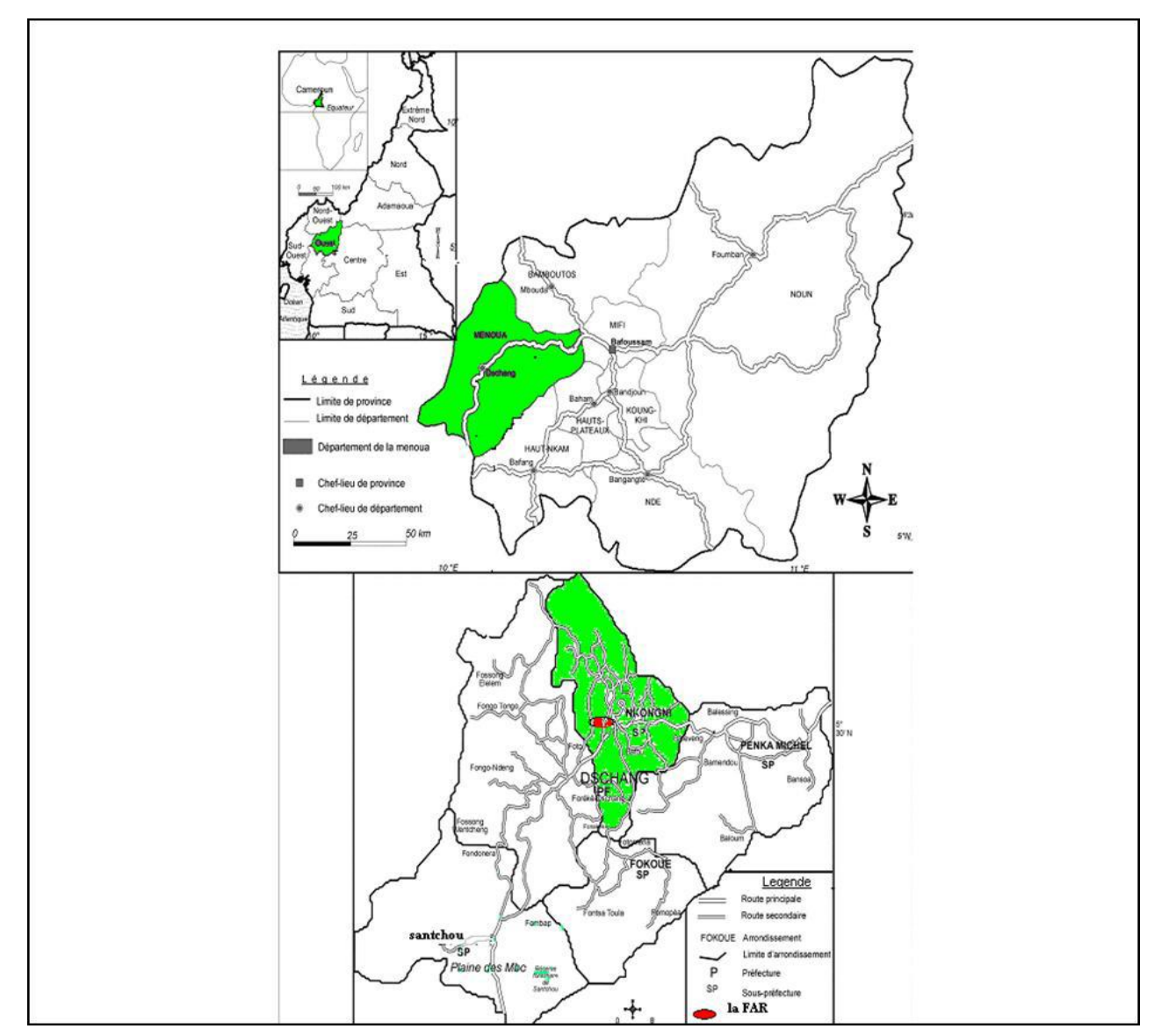

Figure 1 : Carte de la zone de l'étude. 


\section{RESULTATS}

Composition minérale de la paille de riz traitée ou non et de la solution d'extrait de cendre des feuilles de bananier-plantain avant et après traitement

La teneur en minéraux et le $\mathrm{pH}$ ont baissé dans l'extrait après le trempage (Tableau 1). Par contre, le trempage de la paille de riz dans l'extrait a augmenté sa teneur en minéraux.

\section{Composition chimique et teneur en nutriments des différentes rations}

Les teneurs en matière organique, en matière azotée totale et en glucides totaux ont diminué dans les rations contenant la paille traitée à l'extrait de cendre contrairement aux teneurs en cendre, lipides et cellulose brute (Tableau 2). Les teneurs élevées en matière organique, matière azotée totale, $(84,22$ et $8,96 \mathrm{mg} / \mathrm{kg}$ respectivement) ont été obtenues avec les rations PRNT $+\mathrm{Cc}$ et PRNT+ $\mathrm{Cc}$ + PEG. La teneur en glucides totaux la plus élevée a été obtenue avec la ration PRNT et la plus faible a été obtenue avec les rations $\mathrm{PRT}+\mathrm{Cc}$ et PRT $+\mathrm{Cc}+\mathrm{PEG}$. Les teneurs de dMO, UFL, UFV ont diminué dans les rations contenant la paille traitée à l'extrait de cendre.

\section{Digestibilité in vitro \\ Effet de C. calothyrsus associé au PEG sur les paramètres de la digestibilité in vitro de la paille non traitée incubée avec le liquide ruminal caprin}

Bien que l'ajout de Calliandra calothyrsus a permis d'améliorer les paramètres de la digestibilité de la paille de riz non traitée, les valeurs les plus élevées de digestibilité $(\mathrm{P}<0,05)$ ont été obtenues avec le mélange PRNT + Cc + PEG600 (Tableau 3).

Effet de $C$. calothyrsus associé au PEG sur les paramètres de la digestibilité in vitro de la paille traitée incubée avec le liquide ruminal caprin

L'ajout de Calliandra calothyrsus à la paille de riz traitée à l'extrait de cendre a permis d'améliorer de manière significative tous les paramètres de la digestibilité (Tableau 4). De même, l'ajout du PEG à la paille de riz associé au C. calothyrsus a permis d'améliorer de manière significative tous les paramètres de la digestibilité. Par contre, la quantité de gaz, produit après $24 \mathrm{~h}$ d'incubation obtenue avec la paille traitée, a été comparable à celle obtenue avec la paille traitée associée au $C$. calothyrsus. L'ajout du PEG à la paille traitée associée au $C$. calothyrsus a significativement $(\mathrm{p}<0,05)$ augmenté la production de gaz après $24 \mathrm{~h}$ d'incubation. Tout comme avec la paille de riz non traitée, la paille de riz traitée associée au C. calothyrsus et au PEG600 a permis d'enregistrer les valeurs les plus élevées de la digestibilité.

Effet comparé de la paille de riz non traitée et de la paille de riz traitée sur les paramètres de la digestibilité in vitro des différentes rations

La production de gaz après 24 heures d'incubation de la paille de riz traitée à l'extrait de cendre a été significativement $(\mathrm{P}<0,05)$ la plus élevée que celle de la paille non traitée quelle que soit la ration (Figure 1).

L'énergie métabolisable (EM) obtenue avec la paille de riz traitée à l'extrait de cendre a été significativement $(\mathrm{p}<0,05)$ supérieure à celle enregistrée avec la paille de riz non traitée indépendamment des rations (Figure 2).

La comparaison de la masse microbienne comparée obtenue après incubation des différentes rations en fonction de la paille de riz traitée ou non à l'extrait de cendre (Figure 3) montre que la masse microbienne de la paille de riz traitée à l'extrait de cendre a été significativement $(\mathrm{P}<0,05)$ supérieure à celle de la paille non traitée pour les rations R1 et R2. Par ailleurs, la MM de la paille non traitée a été significativement $(\mathrm{P}<0,05)$ supérieur à celle de la paille traitée avec la ration $\mathrm{R} 3$.

Le facteur de cloisement de la paille de riz traitée à l'extrait de cendre (Figure 4). a été significativement $(\mathrm{P}<0,05)$ supérieur à celle de la paille non traitée pour les rations $\mathrm{R} 1$ et R2. A l'inverse, le FC de la paille non traitée a été significativement $(\mathrm{P}<0,05)$ supérieur à celui de la paille traitée avec la ration $\mathrm{R} 3$.

Les acides gras volatils (AGV) comparées obtenus après incubation des différentes rations en fonction de la paille de riz traités ou non à l'extrait de cendre (Figure 5) montre que, les AGV obtenus avec la paille de riz traitée à l'extrait de cendre a été significativement $(\mathrm{p}<0,05)$ supérieure à celle 
enregistrée avec la paille de riz non traitée indépendamment des rations.

La digestibilité in vitro de la matière sèche comparée obtenue après incubation des différentes rations en fonction de la paille de riz traitée ou non à l'extrait de cendre (Figure 6) montre que la digestibilité in vitro de la matière sèche de la paille de riz traitée à l'extrait de cendre a été significativement $(\mathrm{P}<0,05)$ supérieure à celle de la paille non traitée pour les rations R1 et R2. A l'inverse, la DIVMS de la paille non traitée a été significativement $(\mathrm{P}<0,05)$ supérieure à celle de la paille traitée avec la ration R3.

La digestibilité in vitro de la matière organique comparée obtenue après incubation des différentes rations en fonction de la paille de riz traitée ou non à l'extrait de cendre (Figure 7) montre que la digestibilité in vitro de la matière organique obtenue avec la paille de riz traitée à l'extrait de cendre a été significativement $(\mathrm{p}<0,05)$ supérieure à celle enregistrée avec la paille de riz non traitée quelle que soit la ration.

L'azote résiduel comparée obtenue après incubation des différentes rations en fonction de la paille de riz traitée ou non à l'extrait de cendre (Figure 8) montre que, l'azote résiduel obtenu avec la paille de riz non traitée a été significativement $(\mathrm{p}<0,05)$ supérieure à celle enregistrée avec la paille de riz traitée à l'extrait de cendre quelle que soit la ration.

Tableau 1: Composition minérale de la paille traitée ou non et de la solution d'extrait de cendre des feuilles de bananier-plantain avant et après traitement.

\begin{tabular}{|c|c|c|c|c|c|c|}
\hline \multirow{2}{*}{ Echantillons } & \multicolumn{5}{|c|}{ Teneur en minéraux (\%) } & \multirow{2}{*}{ pH } \\
\hline & $\mathbf{N a}$ & $\mathbf{P}$ & Ca & Mg & $\mathbf{K}$ & \\
\hline Extrait initial $(\mathrm{mg} / \mathrm{kg})$ & 175 & 17660 & 2480 & 182 & 3183 & 13,25 \\
\hline Extrait après trempage $(\mathrm{mg} / \mathrm{kg})$ & 168 & 3576 & 0,3260 & 0 & 3036 & 11,33 \\
\hline Paille de riz avant trempage $(\mathrm{mg} / \mathrm{kg})$ & 298 & 584 & 460 & 219 & 4716 & - \\
\hline Paille de riz après trempage $(\mathrm{mg} / \mathrm{kg})$ & 1304 & 936 & 660 & 377 & 16797 & - \\
\hline
\end{tabular}

$\mathrm{Na}=$ Sodium $; \mathrm{P}=$ Phosphore $; \mathrm{Ca}=$ Calcium $; \mathrm{Mg}=$ Magnisium $; \mathrm{K}=$ Potassium.

Tableau 2: Composition chimique et teneur en nutriments des différentes rations.

\begin{tabular}{lcccccc}
\hline Composition chimique & \multicolumn{5}{c}{ Traitements } \\
\cline { 2 - 6 } & PRNT & PRNT+Cc & $\begin{array}{c}\text { PRNT+Cc+ } \\
\text { PEG }\end{array}$ & PRT & PRT+Cc & $\begin{array}{c}\text { PRT+Cc+ } \\
\text { PEG }\end{array}$ \\
\hline MS \% & 97,81 & 96,87 & 96,87 & 4,70 & 91,14 & 91,14 \\
Cendre (\%MS) & 15,36 & 12,65 & 12,65 & 5,70 & 12,88 & 12,88 \\
Matière organique (MO) & 82,45 & 84,22 & 84,22 & 79 & 78,26 & 78,26 \\
Matière azotée totale (MAT) & 4,01 & 8,96 & 8,96 & 2,04 & 7,58 & 7,58 \\
Lipides & 1,94 & 2,31 & 2,31 & 2,05 & 2,38 & 2,38 \\
Parois cellulaire (NDF) & 82,81 & 70,23 & 70,23 & 2,17 & 69,78 & 69,78 \\
Glucides totaux (GT) & 76,5 & 72,95 & 72,95 & 74,91 & 68,3 & 68,3 \\
Cellulose Brute(CB) & 37 & 29,85 & 29,85 & 39,94 & 31,91 & 31,91 \\
dMO (\%MS) & 19,1 & 34,11 & 34,11 & 12,93 & 29,79 & 29,79 \\
MAD (g/100gMOD) & 1,71 & 6,29 & 6,29 & 1,08 & 5,85 & 5,85 \\
UFL/kgMS & 0,58 & 0,71 & 0,71 & 0,52 & 0,67 & 0,67 \\
UFV/kgMS & 0,48 & 0,64 & 0,64 & 0,39 & 0,57 & 0,57 \\
\hline \multicolumn{1}{c}{ PRNT(1) }
\end{tabular}

PRNT $($ témoin $)=$ paille de riz non traitée; $\mathrm{PRNT}+\mathrm{Cc}=$ paille de riz non traitée + Calliandra calothyrsus $; \mathrm{PRNT}+\mathrm{Cc}+\mathrm{PEG}=$ paille de riz non traitée + Calliandra calothyrsus +Polyéthylène glycol; PRT= paille de riz traitée à 10\% d'extrait de cendre; $\mathrm{PRT}+\mathrm{Cc}=$ paille de riz traitée à $10 \%$ d'extrait de cendre + Calliandra calothyrsus; ; $\mathrm{PRT}+\mathrm{Cc}+\mathrm{PEG}=$ paille de riz traitée à $10 \%$ d'extrait de cendre+ Calliandra calothyrsus + Polyéthylène glycol; UFL = unité fourragère lait; UFV = unité fourragère viande; MAD = matière azotée digestible. 
Tableau 3 : Effet de C. calothyrsus associé au PEG sur les paramètres de la digestibilité in vitro de la paille non traitée incubée avec le liquide ruminal caprin.

\begin{tabular}{|c|c|c|c|c|c|c|c|c|}
\hline Rations & $\begin{array}{c}\text { GP après } \\
\text { 24h } \\
(\mathbf{m l} / 500 \mathrm{mg})\end{array}$ & $\begin{array}{c}\text { EM } \\
(\mathrm{MJ} / \\
\mathrm{kgMS})\end{array}$ & $\begin{array}{l}\text { MM } \\
(\mathbf{m g})\end{array}$ & $\begin{array}{c}\mathrm{FC} \\
(\mathrm{mg} / \mathrm{ml})\end{array}$ & $\begin{array}{c}\text { AGV } \\
(\mathrm{mmol} / \\
40 \mathrm{ml})\end{array}$ & $\begin{array}{c}\text { DIVMS } \\
(\%)\end{array}$ & $\begin{array}{c}\text { DIVMO } \\
(\%)\end{array}$ & $\begin{array}{c}\text { NDF- } \\
\text { N }\end{array}$ \\
\hline PRNT & $29,28^{\mathrm{c}}$ & $6,41^{\mathrm{c}}$ & $83,59^{c}$ & $1,92^{\mathrm{c}}$ & $0,64^{\mathrm{c}}$ & $28,04^{\mathrm{c}}$ & $43,71^{\mathrm{c}}$ & $0,32^{\mathrm{c}}$ \\
\hline $\mathrm{PRNT}+\mathrm{Cc}$ & $32,63^{\mathrm{b}}$ & $7,15^{\mathrm{b}}$ & $169,56^{\mathrm{b}}$ & $2,92^{\mathrm{b}}$ & $0,72^{\mathrm{b}}$ & $47,14^{\mathrm{b}}$ & $48,74^{\mathrm{b}}$ & $0,78^{\mathrm{b}}$ \\
\hline $\mathrm{PRNT}+\mathrm{Cc}+\mathrm{PEG}$ & $35,96^{\mathrm{a}}$ & $7,60^{\mathrm{a}}$ & $193,89^{\mathrm{a}}$ & $2,92^{\mathrm{a}}$ & $0,77^{\mathrm{a}}$ & $52,46^{\mathrm{a}}$ & $51,70^{\mathrm{a}}$ & $0,41^{\mathrm{a}}$ \\
\hline ESM & 0,47 & 0,065 & 0,75 & 0,51 & 0,01 & 0,58 & 0,42 & 0,02 \\
\hline $\mathrm{P}$ & 0,00 & 0,00 & 0,00 & 0,00 & 0,00 & 0,00 & 0,00 & 0,00 \\
\hline
\end{tabular}

a, b, c : les moyennes portant la même lettre dans la même colonne sont comparables au seuil de 5\%.

$\mathrm{PRNT}=$ paille de riz non traitée $; \mathrm{PRNT}+\mathrm{Cc}=$ paille de riz non traitée + Calliamdra calothyrsus $; \mathrm{PRNT}+\mathrm{Cc}+\mathrm{PEG}==$ paille de riz non traitée + Calliamdra calothyrsus +Polyéthylène glycol; ESM : Erreur standard de la moyenne ; P : Probabilité. GP : gaz produit ; EM : énergie métabolisable ; MM : masse microbienne ; FC: facteur de cloisement ; AGV : acides gras volatils ; DIVMS : digestibilité in vitro de la matière sèche ; DIVMO : digestibilité in vitro de la matière organique.

Tableau 4 : Effet de C. calothyrsus associé au PEG sur les paramètres de la digestibilité in vitro de la paille traitée incubée avec le liquide ruminal caprin.

\begin{tabular}{lcccccccc}
\hline Rations & $\begin{array}{c}\text { GP après } \\
\mathbf{2 4 h} \\
(\mathbf{m l} / \mathbf{5 0 0} \mathbf{m g})\end{array}$ & $\begin{array}{c}\text { EM } \\
(\mathbf{M J} / \mathbf{k g M S})\end{array}$ & $\begin{array}{c}\text { MM } \\
(\mathbf{m g})\end{array}$ & $\begin{array}{c}\text { FC } \\
(\mathbf{m g} / \mathbf{m l})\end{array}$ & $\begin{array}{c}\text { AGV } \\
(\mathbf{m m o l} / \mathbf{4 0 m l})\end{array}$ & $\begin{array}{c}\text { DIVMS } \\
(\boldsymbol{\%})\end{array}$ & $\begin{array}{c}\text { DIVMO } \\
(\mathbf{\%})\end{array}$ & $\begin{array}{c}\text { NDF- } \\
\mathbf{N}\end{array}$ \\
\hline PRT & $36,95^{\mathrm{b}}$ & $7,34^{\mathrm{c}}$ & $111,37^{\mathrm{c}}$ & $2,1^{\mathrm{c}}$ & $0,83^{\mathrm{c}}$ & $38,63^{\mathrm{c}}$ & $49,52^{\mathrm{c}}$ & $0,29^{\mathrm{c}}$ \\
PRT+ Cc & $36,72^{\mathrm{b}}$ & $7,61^{\mathrm{b}}$ & $127,56^{\mathrm{b}}$ & $2,21^{\mathrm{b}}$ & $0,82^{\mathrm{b}}$ & $41,07^{\mathrm{b}}$ & $51,51^{\mathrm{b}}$ & $0,56^{\mathrm{a}}$ \\
PRT + Cc+ PEG & $40,02^{\mathrm{a}}$ & $8,05^{\mathrm{a}}$ & $218,63^{\mathrm{a}}$ & $3,08^{\mathrm{a}}$ & $0,9^{\mathrm{a}}$ & $61,78^{\mathrm{a}}$ & $54,45^{\mathrm{a}}$ & $0,31^{\mathrm{b}}$ \\
ESM & 0,23 & 0,03 & 0,66 & 0,03 & 0,01 & 0,57 & 0,21 & 0,01 \\
P & 0,00 & 0,00 & 0,00 & 0,00 & 0,00 & 0,00 & 0,00 & 0,00 \\
\hline
\end{tabular}

$\mathrm{a}, \mathrm{b}, \mathrm{c}$ : les moyennes portant la même lettre dans la même colonne sont comparables au seuil de 5\%. PRT = paille de riz traitée à $10 \%$ d'extrait de cendre; $\mathrm{PRT}+\mathrm{Ca}=$ paille de riz traitée à $10 \%$ d'extrait de cendre + Calliamdra calothyrsus; $\mathrm{PRT}+\mathrm{Ca}+\mathrm{PEG}=$ paille de riz traitée à $10 \%$ d'extrait de cendre + Calliamdra calothyrsus +Polyéthylène glycol; ESM : Erreur standard de la moyenne ; P : Probabilité. GP : gaz produit ; EM : énergie métabolisable ; MM : masse microbienne ; FC: facteur de cloisement; AGV : acides gras volatils; DIVMS : digestibilité in vitro de la matière sèche ; DIVMO : digestibilité in vitro de la matière organique. 


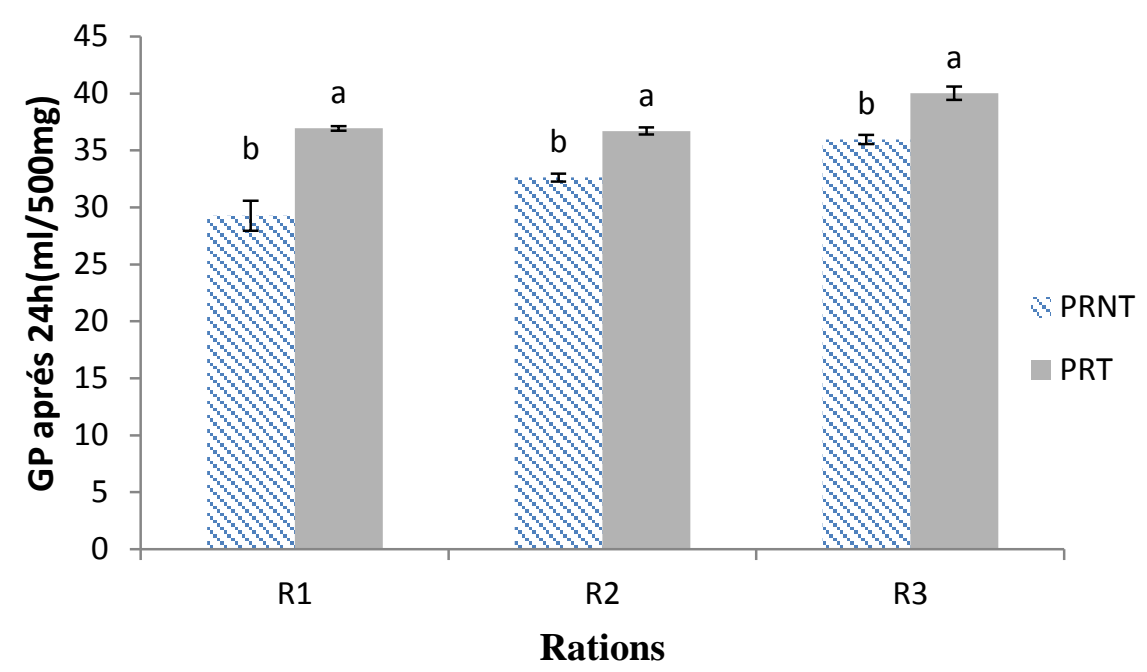

a, b: Les barres affectées de la même lettre pour la même ration ne diffèrent pas significativement $(p>0,05)$. R1= paille de riz ; R2=paille de riz + Calliandra calothyrsus $; \mathrm{R} 3=$ paille de riz + Calliandra calothyrsus + Polyéthylène glycol ; GP= gaz produit.

Figure 2: Production comparée de gaz après 24 heures d'incubation des différentes rations en fonction de la paille de riz traitée ou non à l'extrait de cendre.

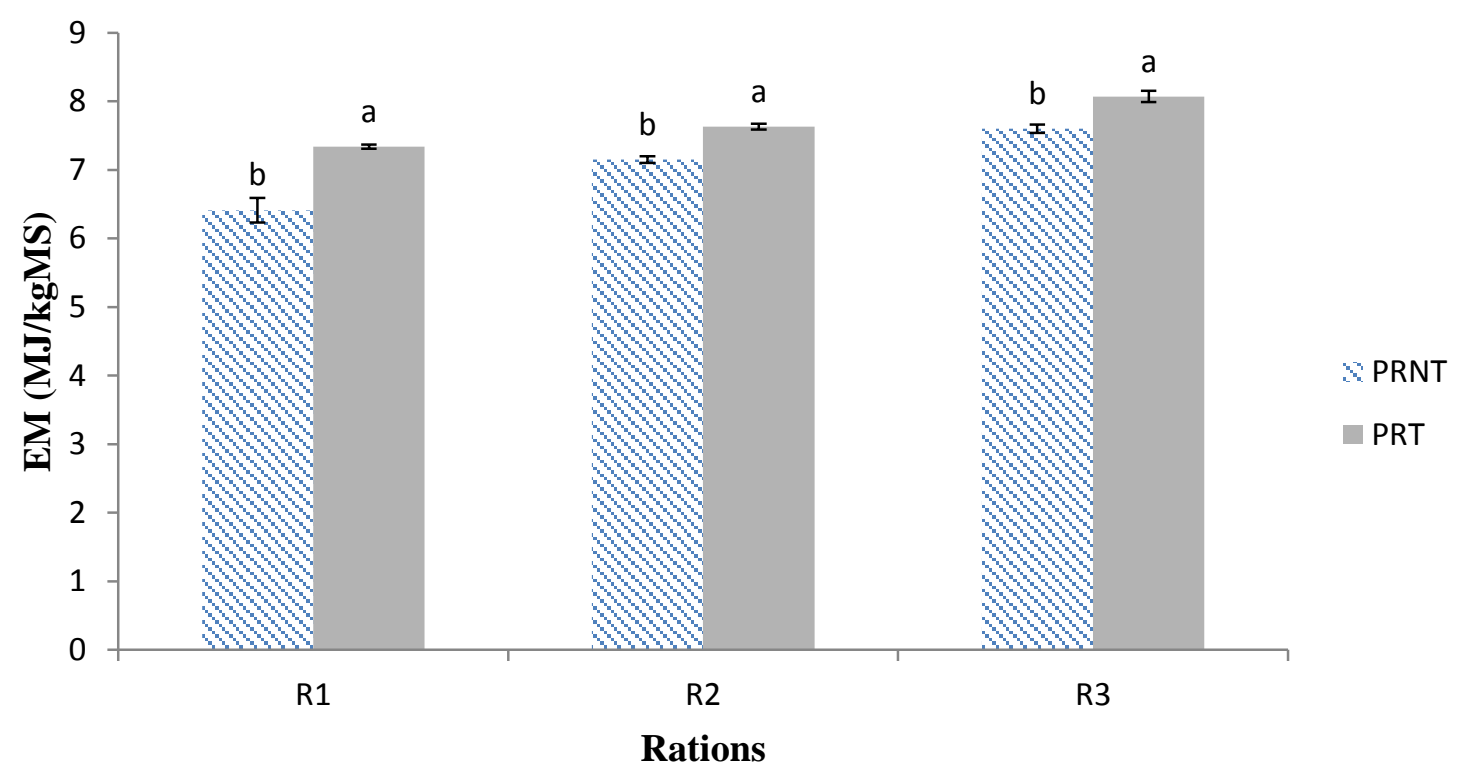

a, b: Les barres affectées de la même lettre pour la même ne diffèrent pas significativement $(p>0,05)$. R1= paille de riz $\mathrm{R} 2=$ paille de riz + Calliandra calothyrsus ; R3= paille de riz + Calliandra calothyrsus + Polyéthylène glycol ; EM= énergie métabolisable.

Figure 3: Energie métabolisable comparée obtenue après incubation des différentes rations en fonction de la paille de riz traitée ou non à l'extrait de cendre. 


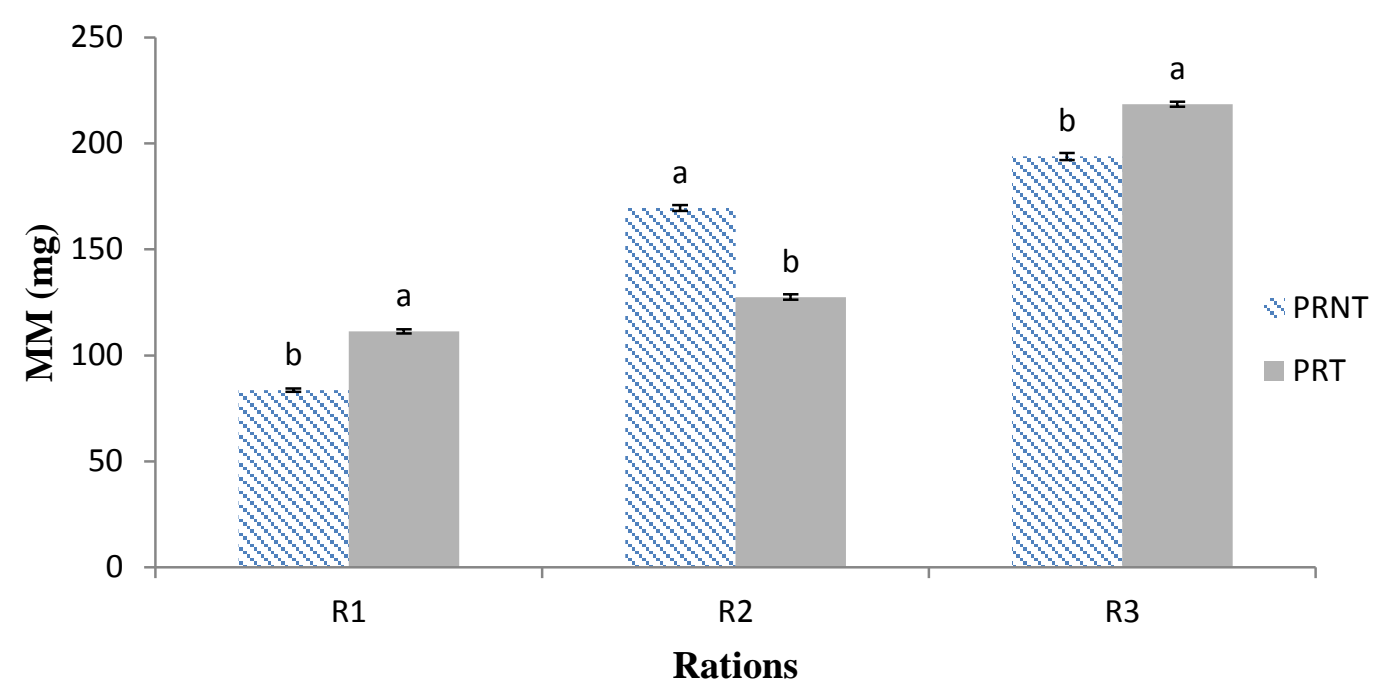

$a$, $b$ : Les barres affectées de la même lettre pour la même ration ne diffèrent pas significativement $(p>0,05)$. R1= paille de riz $\mathrm{R} 2=$ paille de riz + Calliandra calothyrsus $; \mathrm{R} 3=$ paille de riz + Calliandra calothyrsus + Polyéthylène glycol ; MM= Masse microbienne.

Figure 4: Masse microbienne comparée obtenue après incubation des différentes rations en fonction de la paille de riz traitée ou non à $10 \%$ d'extrait de cendre.

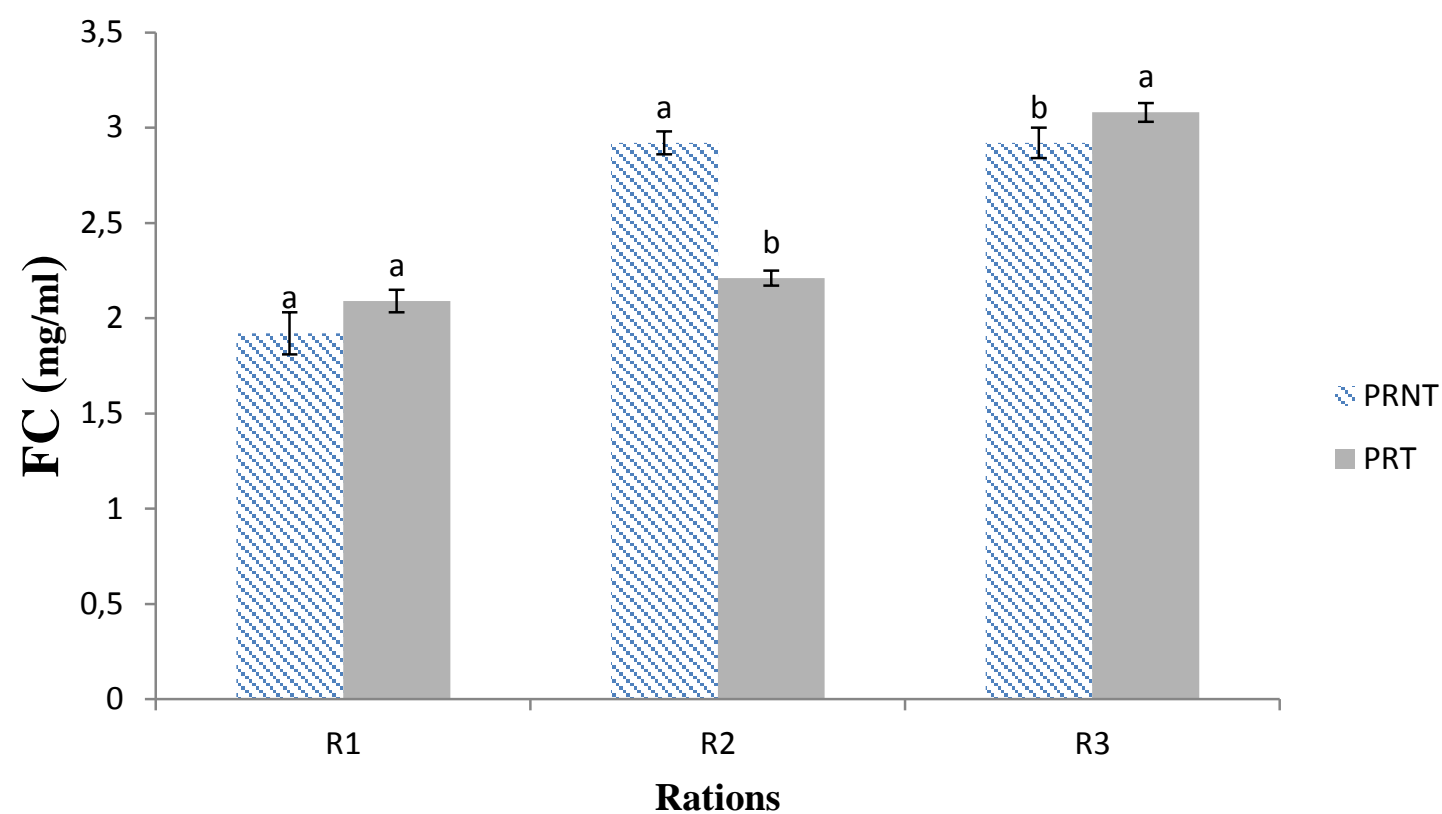

a, b: Les barres affectées de la même lettre pour la même ration ne diffèrent pas significativement $(p>0,05)$. R1= paille de riz $\mathrm{R} 2=$ paille de riz + Calliandra calothyrsus $; \mathrm{R} 3=$ paille de riz + Calliandra calothyrsus + Polyéthylène glycol FC= Facteur de cloisement.

Figure 5: Facteur de cloisement comparée obtenu après incubation des différentes rations en fonction de la paille de riz traitée ou non à l'extrait de cendre. 


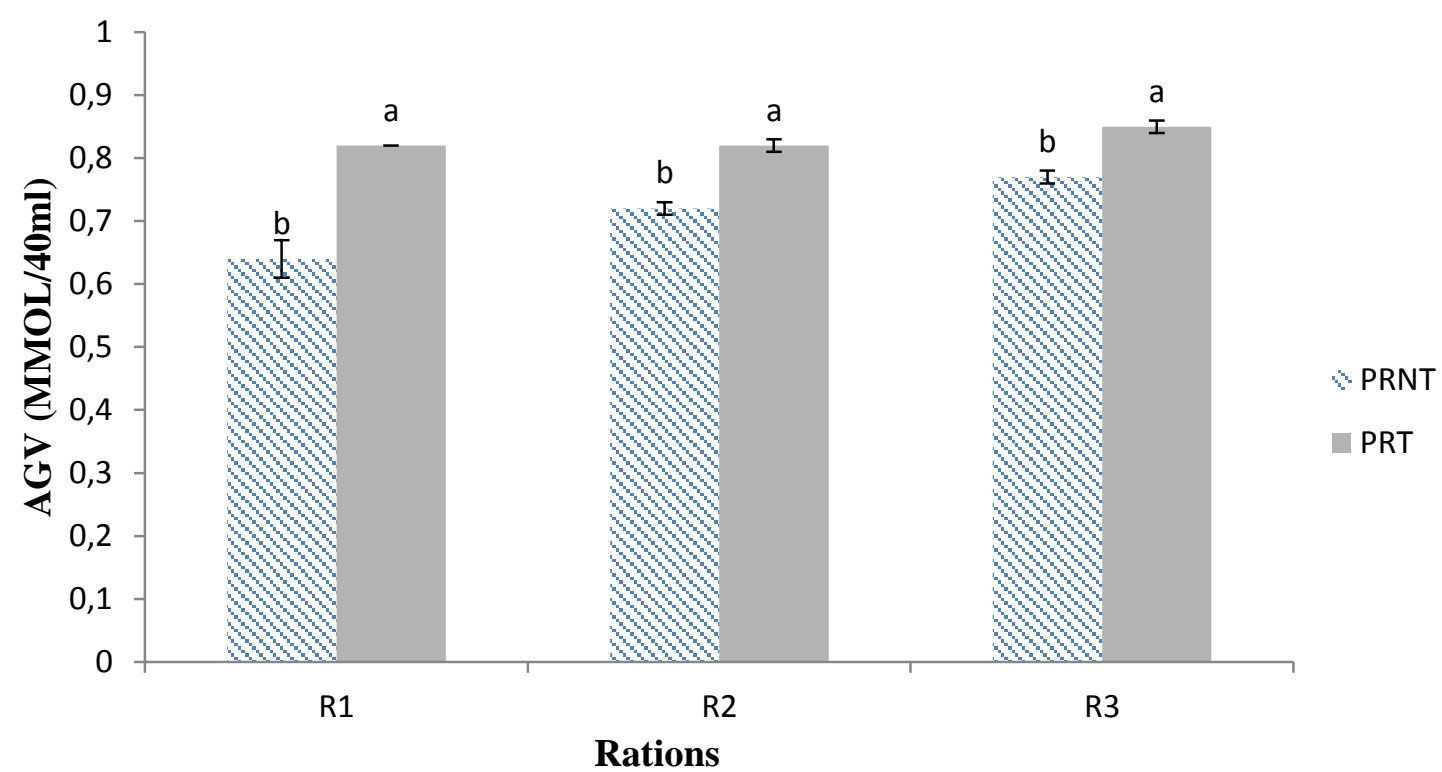

a, b: Les barres affectées de la même lettre pour la même ration ne diffèrent pas significativement (p>0,05). R1= paille de riz $\mathrm{R} 2=$ paille de riz + Calliandra calothyrsus $; \mathrm{R} 3=$ paille de riz + Calliandra calothyrsus + Polyéthylène glycol; AGV= Acides gras volatils.

Figure 6: Acides gras volatils comparés obtenus après incubation des différentes rations en fonction de la paille de riz traitée ou non à l'extrait de cendre.

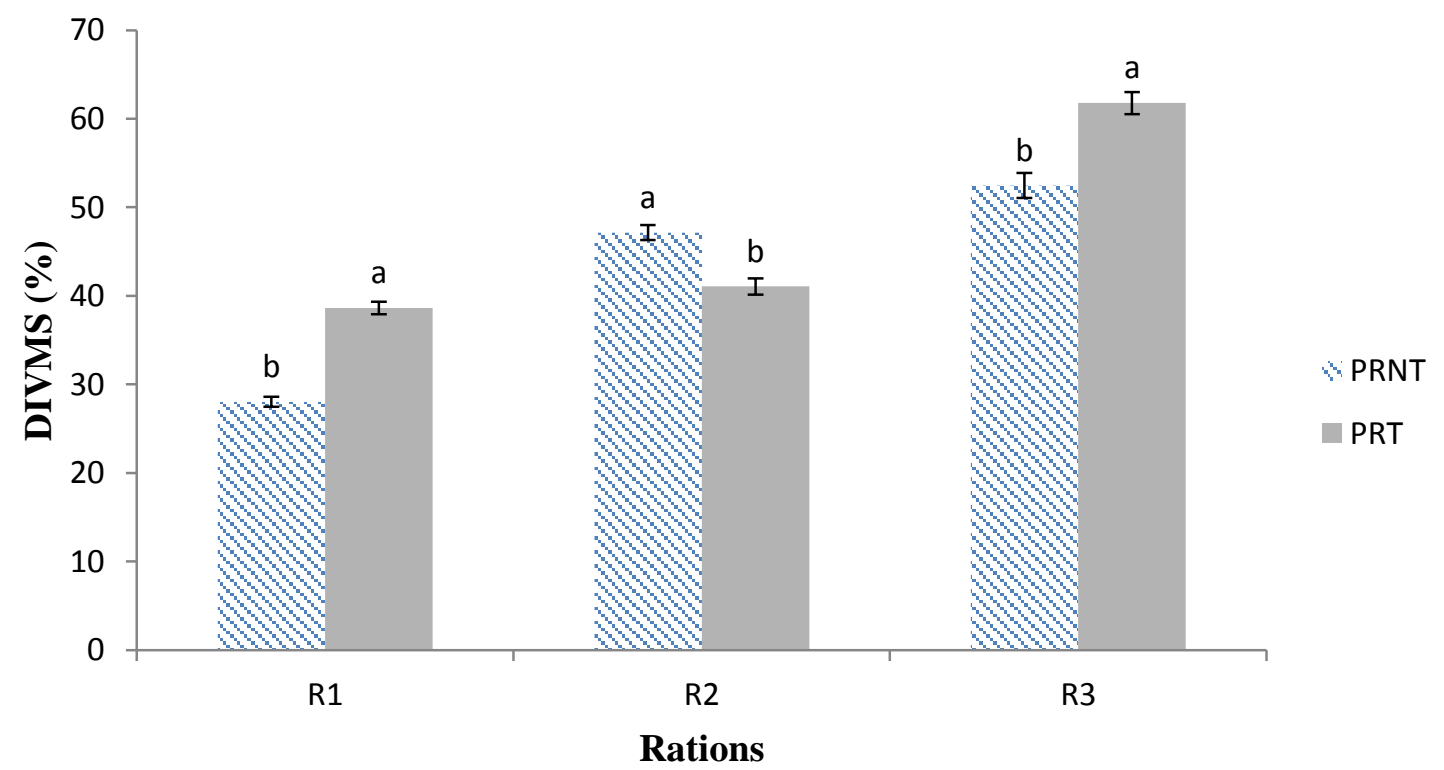

$\mathrm{a}, \mathrm{b}$ : Les barres affectées de la même lettre pour la même ration ne diffèrent pas significativement ( $>0,05)$. R1=paille de riz R2= paille de riz + Calliandra calothyrsus $; \mathrm{R} 3=$ paille de riz + Calliandra calothyrsus + Polyéthylène glycol; DIVMS= Digestibilité in vitro de la matière sèche.

Figure 7: Digestibilité in vitro de la matière sèche (DIVMS) comparée obtenue après incubation des différentes rations en fonction de la paille de riz traitée ou non à l'extrait de cendre. 


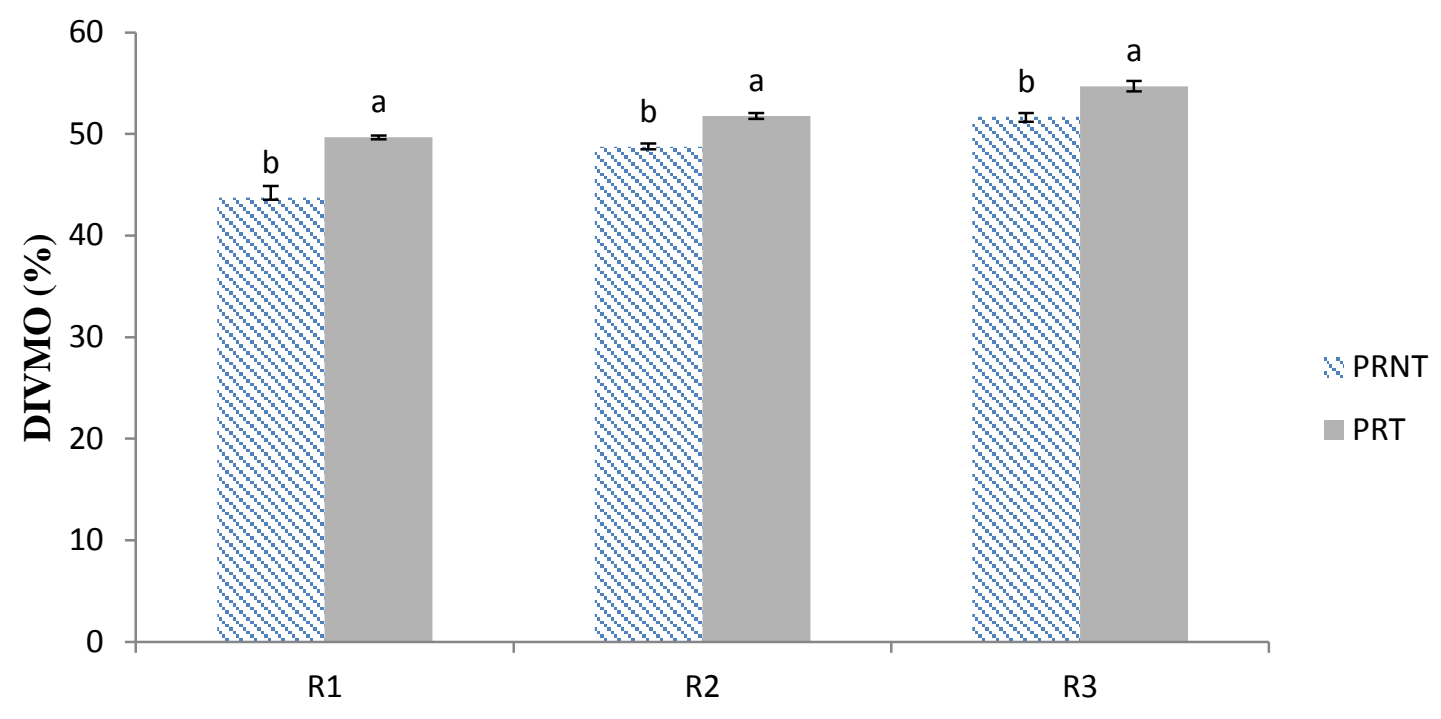

\section{Rations}

a, b: Les barres affectées de la même lettre pour la même ration ne diffèrent pas significativement $(p>0,05)$. R1=paille de riz $\mathrm{R} 2=$ paille de riz + Calliandra calothyrsus ; R3= paille de riz + Calliandra calothyrsus + Polyéthylène glycol ; DIVMO= Digestibilité in vitro de la matière organique.

Figure 8: Digestibilité in vitro de la matière organique (DIVMO) comparée obtenue après incubation des différentes rations en fonction de la paille de riz traitée ou non à l'extrait de cendre.

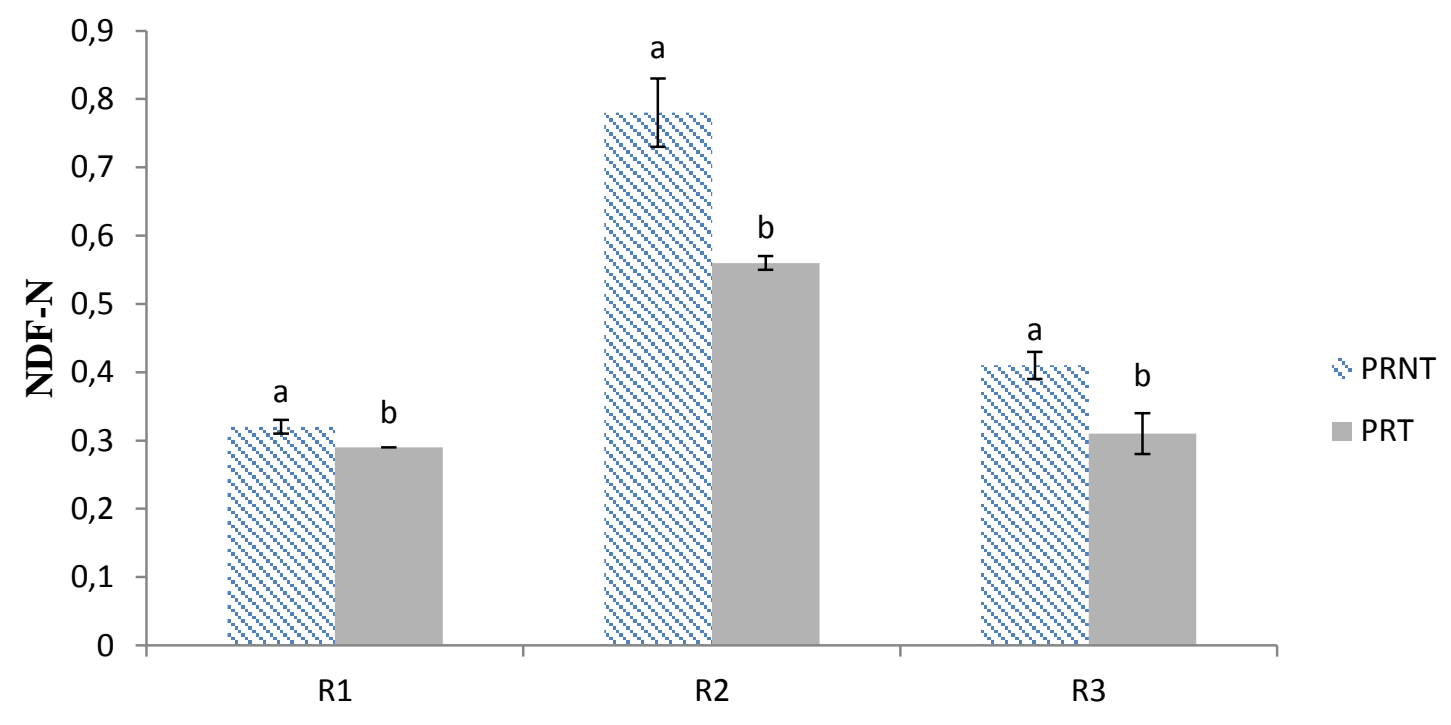

\section{Rations}

a, b: Les barres affectées de la même lettre pour la même ration ne diffèrent pas significativement ( $>0,05)$. R1=paille de riz $\mathrm{R} 2=$ paille de riz + Calliandra calothyrsus ; R3= paille de riz + Calliandra calothyrsus + Polyéthylène glycol ; NDF-N=Azote résiduel.

Figure 9: Effet de l'Azote résiduel comparée obtenue après incubation des différentes rations en fonction de la paille de riz traitée ou non à l'extrait de cendre. 


\section{DISCUSSION}

La composition minérale de la paille de riz dans cette étude a été influencée par le traitement à l'extrait de cendre. Les teneurs des minéraux ont significativement augmenté avec la paille de riz traitée ceci en diminuant la teneur en minéraux dans la solution d'extrait de cendre, ce résultat est similaire à ceux de Laswai et al. (2007). En effet, selon ces auteurs, la paille absorbe une partie des minéraux lors du traitement à l'extrait de cendre.

La composition chimique de la paille de riz a été influencée par le traitement à l'extrait de cendre associé à Calliandra calothyrsus. Les teneurs en constituants organiques ont diminués avec le traitement à l'extrait de cendre associé à $C$. calothyrsus. La teneur en cendre de la paille traitée à l'extrait de cendre a été plus élevée que celle de la paille non traitée. Ce résultat est similaire à ceux rapportés par Laswai et al. (2007) ; Rahman et al. (2009) et Kanyinji et al. (2014). Selon ces auteurs, cette forte teneur en cendre dans la paille traitée pourrait s'expliquer par la présence de minéraux dans l'extrait. La teneur en paroi cellulaire (NDF) de la paille traitée a baissé par rapport à la paille non traitée. Des observations semblables ont été faites Laswai et al. (2007) et Rahman et al. (2009) qui l'explique par le fait que les constituants de la paroi cellulaire de la paille ont été attaqués lors du traitement, ce qui a entraîné leur fragilisation. La teneur en MAT (2,02\%MS) contenue dans la paille traitée est faible par rapport à celle rapportée par Laswai et al. (2007) (6\%MS), par Rahman et al. (2009) $(3,04 \% \mathrm{MS})$ et par Kanyinji et al. (2014) $(4,9 \% \mathrm{MS})$ avec la paille traitée. Cette baisse de MAT pourrait s'expliquer par le type de combustible utilisé pour la fabrication de l'extrait qui aurait lors du traitement entraîné la dégradation d'une partie d'azote. Toutefois, ces résultats sont inférieurs de ceux rapportés par Laswai et al. (2007) sur la digestibilité in vivo de la paille de riz $(63,3 \%$ et $68,5 \%$ respectivement). Cette différence pourrait être due au type et à la variété de la paille, mais aussi bien au type de combustible utilisé. Toutefois, l'apport d'une source de protéine
(Calliandra calothyrsus) associé au PEG permet de rehausser la digestibilité de la matière sèche et de la matière organique à 61,76 et $54,70 \%$ respectivement.

Le FC et la masse microbienne ont été améliorés par l'ajout de $C$. calothyrsus associé au PEG dans la paille de riz traitée $(3,08$ $\mathrm{mg} / \mathrm{ml}$ ). Toutefois, Getachew et al. (2000b) rapportent qu'en absence et associé au PEG, le facteur de cloisement de Calliandra calothyrsus est situé entre 3,1 et $16 \mathrm{mg} / \mathrm{ml}$ respectivement. Le FC de cette étude en présence du PEG correspond à celui obtenu par ces auteurs en absence du PEG. Lors du traitement, Ceci pourrait s'expliquer par le fait que le traitement a restauré l'effet du PEG sur le FC en augmentant la masse microbienne, et d'autre part est dû à l'effet dépressif du tannin sur la dégradation de la MO qui pourrait empêcher au PEG en présence de la paille de réduire la masse microbienne.

Le NDF-N a significativement diminué avec l'ajout de Calliandra associé au PEG dans la paille $(0,41 \%)$, ces observations sont similaires à ceux faites par Jetana et al. (2011) sur la digestibilité in vivo de la paille de riz associé à Leuceana leucocephala et au PEG $(0,46 \%)$ ce qui pourrait affirmer l'affinité de fixation du PEG aux sites des tanins sur lesquels les protéines auraient dû se fixer et devenir indisponibles aux micro-organismes du rumen et aux activités métaboliques.

La quantité de gaz produite, l'EM et les AGV des différentes pailles ont été significativement élevées avec la ration contenant $C$. calothyrsus associé au PEG sur le liquide ruminal caprin. Ce résultat concorde avec celui de Silanikove (2000) qui observent que le liquide ruminal de la chèvre a une grande habilité à tolérer les effets négatifs associés aux concentrations de plus en plus élevées de composés secondaires tels que la silice et la lignine. Ainsi, les chèvres contiendraient, dans leur tube digestif, des microorganismes qui digéreraient les fourrages très ligneux (Silanikove, 2000).

\section{Conclusion}

De cette étude, il ressort que le traitement à l'extrait de cendre a amélioré la 
composition minérale de la paille de riz. L'ajout de Calliandra calothyrsus a permis de rehausser la teneur en matière azoté totale (MAT) de la paille. L'ajout de Calliandra calothyrsus associé au PEG 6000 a permis d'augmenter de manière significative tous les paramètres de la digestibilité in vitro la paille de riz non traitée et de la paille de riz traitée à l'extrait de cendre. De manière générale la paille traitée à l'extrait de cendre a permis d'obtenir les meilleurs résultats quel que soit la ration considérée. Cette paille de riz pourrait être utilisée dans l'alimentation des ruminants sous réserve des essais in vivo.

\section{CONFLIT D'INTERETS}

Les auteurs déclarent qu'il n'existe aucun conflit d'intérêts pour cet article.

\section{CONTRIBUTIONS DES AUTEURS}

FT, JL et EM ont contribué à l'élaboration du projet et la rédaction scientifique; FENM et BZF ont contribué à la relecture; $\mathrm{AC}$ et FDN ont contribué à la collecte des données; EPT a contribué à la coordination générale et au conseil scientifique.

\section{REFERENCES}

AOAC (Association of Official Analytical Chemist). 2000. Official Methods of Analysis $\quad\left(17^{\text {th }}\right.$ edition): AOAC. Washington D.C.

FAOSTAT. 2009. FAOSTAT data base. Accessible via FAO home page at http://apps.fao.org/ Food and Agriculture Organization.

Frutos P, Hervas G, Ramos G, Giraldez FJ, Mantecon AR. 2002. Condensed tannin content of several shrub species from a mountain area in northern Spain, and its relationship to various indicators of nutritive value. Animal Feed Science and Technology, 95: 215-226. CSIC. Apdo 788. 24080-León.

Heuze V, Tran G. 2013. Rice straw. Feedipedia.org. A programme by INRA, CIRAD, AFZ and FAO. http://www.feedipedia.org/node/557 Last updated on March 15, 2013, 15:12.
Jetana T, Vongpipatana C, Usawang S, Thongruay S. 2011. The use of tropical protein-rich leaves as supplements to Thai swamp buffalo receiving a basal diet of rice straw and treated leucaena (Leucaena leucocephala) Trop Anim. Health Prod., 43: 57-67. http//doi.org/ 10.1007/s11250-010-9654-7. Epub 2010 Jul 15

Kanyinji F, Chongo J, Simbaya J. 2014. Intake and Digestibility of Rhodes Grass (Chloris Gayana) Hay Treated with Graded Levels of Concentration of Banana Leaf Ash Solution in Local Goats. Journal of Animal Production Advances, $\quad$ 4(6): 448-454. http://www.grjournals.com/index.php/JA $\mathrm{PA} /$ article/view/187

Laswai G, Mtamakaya J, Kimambo A, Aboud A, Mtakwa P. 2007. Dry matter intake, in vivo nutrient digestibility and concentration of minerals in the blood and urine of steers fed rice straw treated with wood ash extract. Animal Feed Science and Technology, 137: 25-34.

Lemoufouet J, Tendonkeng F, Miégoué E, Fogang Zogang B, Matumuini FNE, Mboko AV, Boukila B, Pamo ET. 2016. Digestibilité in vitro des chaumes de maïs traités à l'urée ou aux fientes de poules associés à la mélasse chez les petits ruminants. Livestock Research for Rural Development, 28(2): 2016. http://www.lrrd.org/lrrd28/2/lemo28027. htm

Makkar HPS. 2002. Application of the in vitro method in the evaluation of feed resources, and enhancement of nutritional value of tannin-rich tree/browse leaves and agro-industrial by-products. In Development and field Evaluation of Animal Feed Supplementation Packages. Proceeding of the final review meeting of an IAEA Technical Co-operation Regional AFRA Project organized by the Joint FAO/IAEA Division of Nuclear Techniques in Food and Agriculture and held in Cairo, Egypt, 25-29 November 2000. Pp 23-40. 
Menke KH, Steingass H. 1988. Estimation of the energetic feed value obtained from chemical analysis and in vitro gas production using rumen fluid. Animal Research and Development, 28: 7-55.

Menke KH, Raab L, Salewski A, Steingass H, Fritz D. Schneider W. 1979. The estimation of digestibility and metabolizable energy content of ruminant feedstuffs from gas production when they are incubated with rumen liquor. Journal of Agricultural Science, 93: 217-222.

Pamo TE, Kana JR, Tendonkeng F, Betfiang ME. 2004. Digestibilité in vitro de Calliandra calothyrsus en presence du Polyethylène glycol et de Brachiaria ruziziensis, Trypsacum laxum ou Pennisetum purpurum au Cameroun. Livestock Research for Rural Development, $\quad \mathbf{1 6}(\mathbf{7})$. http://www.lrrd.org/lrrd16/7/tedo16049. $\mathrm{htm}$

Pamo Tedonkeng E, Boukila B, Fonteh FA, Tendonkeng F, Kana JR. 2005. Composition chimique et effet de la supplémentation avec Calliandra calothyrsus et Leucaena leucocephala sur la production laitière et la croissance des chevreaux nains de Guinée. Livestock Research for Rural
Development, 17(30). Retrieved May 13, 2018, from http://www.lrrd.org/ lrrd17/3/tedo17030.htm.

Rahman MM, Alam MR, Aminand MR, Das NG. 2010. Comparative study of the nutritive values of the different varieties of rice straw. Bangladesh Journal of Animal Science, 39(1\&2): 75 - 82.

Tendonkeng F, Boukila B, Pamo TE, Mboko AV, Zogang FB, Matumuini NEF. 2011. Effets direct et résiduel de différents niveaux de fertilisation azotée sur la composition chimique de Brachiaria ruziziensis à la floraison à l'Ouest Cameroun. International Journal of Biological and Chemistry Sciences, 5(2): 570-585.

DOI: http://dx.doi.org/10.4314/ijbcs.v5i2.72115

Van Soest JP,Robertson JB. 1985. Laboratory Manual for Animal Science. Cornelle University: New York, USA.

Yaning Zhang AE, Ghaly, Bingxi L. 2012. Physical properties of rice residues as affected by variety and climatic and cultivation conditions in three continents. American Journal of Applied Sciences, 9(11): 1757-1768 DOI: 10.3844/ajassp.2012.1757.1768. 